\title{
Editorial
}

\section{Relating Systems Thinking and Design II} Theoretical Evolution in Systemic Design

We have joined two issues of FORMakademisk to accommodate two sets of articles developed from remarkable early work presented at the 2013 Relating Systems Thinking to Design Symposium in Oslo. We organized these papers into a theory set, and a set for practice of systemic design, although most of these theoretical works are deeply informed by design and planning practices. The theory issue, Theoretical Evolution in Systemic Design, comprises the perspectives of scholars contributing new work crossing the former boundaries between systems theory and design thinking.

These papers are viewed as theoretical primarily due to their strong basis in systems science or human system theories that inform design practices in a generalizable way. While most of the practice-led papers in Issue 7:3 Relating Systems Thinking and Design I: Practical Advances in Systemic Design relate to a specific case or context, which may or may not apply to other cases, the theoretical papers inform our body of knowledge and may inform and underpin other design disciplines. While these works are informed by design applications, such as participatory and group design contexts, design-led engineering problems, and service systems, they all contribute to foundations for explanatory, descriptive or normative theory in systemic design.

Systemic design is uniquely distinguished by its co-evolution with systems theory, which connects a deep well of scientific principles, epistemologies, and interpretive methods to design thinking. Yet perhaps systems and complexity theory are not the outliers in design, but the notion of design theory itself. While design journals continue to publish brilliant, unread theoretical papers, the pragmatic field of design, much as with engineering, remains unmoved by design theory (or any theory). Even design science reveals a field largely informed by methodology rather than conceptual theory. However, while design theory has been inspired by cognitive psychology, behavioural economics, and organizational studies, we have little agreement toward producing a canon of essential design theories.

\section{Influence of Systemics on Design Theory}

Some of the most influential design theories have emerged from systemics, including HCI theories, Flores and Winograd (1986), Krippendorff's Semantic Turn (2006), Alexander's Nature of Order (2002), and Nelson and Stolterman's The Design Way (2012). Judging from the arguments across design discourses, our theory base typically refers to a small number of total references, often citing the same roots of Buchanan's Wicked Problems (1992), Archer's design research (1981), and Cross' Designerly Ways of Knowing (1982). There is even little agreement within service design to incorporate the strong theories from service systems science, which could be argued to contribute significantly to the functional design and evaluation of human-centred services. In the last decade, it appears Design has won the empirical argument, claiming its significance, impact and necessity in all domains of use. Yet we have neglected the ability to systematically explain why that is so.

Most design disciplines are characterized by constructive invention and reflection/ evaluation, pragmatic proofs of workability, not deductive theoretical explanations. Advanced design scholars and practitioners continually reinvent methods and processes 
contextually, as a user base or research mandate might require. Design does not follow the scientific approach to methods as found in systems practice, based in bio, eco, and human sciences and developed over years of peer review and action research. Design theories also do not "scaffold" well, in the sense of building on one another's contributions toward a greater applicability of knowledge. Perhaps if we built design theory upon systemic explanations, adapting social, technical, and cultural systems and complex and cybernetic behaviours, we might be rewarded by the immediate thrust of historical support these underpinnings lend to design applications, from historical craft knowledge to the most intangible futurist speculation.

Across all its various fields design is characterized by its richness of methods, its object-oriented bias toward making, an iterative refinement toward ideal states that do not yet exist, and the necessity of abductive reasoning. But while design theory can often appear thin or inapplicable across design disciplines, when informed by systemic theories and systematic practices we can discover new value in its applicability to many contexts and problem areas. In practical terms, we can draw from the theories proposed by systemic design authors to construct well-reasoned explanations of behaviour, well-supported foresight models, and to define rationale for design decisions in highly complex problems. We can learn from their general principles, determine evaluation criteria, and draw hypotheses for their explanation for novel design contexts. It may be too early to propose, but I find it possible that systemic theories will connect the design disciplines and their social applications. As originally proposed by Kenneth Boulding, general systems theory was conceived as a "skeleton" to structure human knowledge across all scientific fields. How might the disparate design fields of architecture, service design, and urban design benefit from a coherent view of humancentred design based on second-order cybernetics? Could we not frame normative proposals for action based on Luhmann, Ozbekhan, or Banathy social system models?

Every system theory or model - social systems design, living systems, anticipatory systems, adaptive systems, ecosystem theory, information ecologies, critical systems, and complexity theory - is a point of view which we can adopt in design. Every systems theory provides a rationale and guideline for understanding individual and social human behavior, interaction with environments, and a position on the future. Systems theories enjoy a deep canon of literature and with strong roots in science and research method. As designers engage with ever more complex problem areas - global services, evolving organizational models, multi-stakeholder policy planning and the redesign of institutions - we have to draw on a basis other than individual creativity and contemporary "design thinking" methods. Systems theories can co-evolve with a new school of design theory to resolve informed action on today's highly-resilient wicked problems, and deal effectively with challenging, contested and high-stakes challenges.

\section{Reviewing the Contents of the Issue}

The issue presents six works which represent in various ways the evolutionary path of systemic design thinking and theory today.

Wolfgang Jonas frames a theory for Practice-Based Design Research as a process for researching design as a transition from "knowns to unknowns." He takes issue with the requirements for control and prediction, necessary for design outcomes (practice) but inherently at odds with the complexity of designing the new or unknown. Jonas connects the issues of systemic complexity and design reasoning at several levels, showing the paradoxes, blind spots, and irresolvability in our thinking within design practices. He proposes a Research through Design model that cuts through the gaps in reasoning and reality, by instantiating models and objects employed as research instruments for design rationale. His 
work advances a second-order cybernetics view of research inquiry, and proposes the value of Ulrich's critical systems view in design research.

David Ing (past president of ISSS) crosses over from systemics to design with his proposal for system theories that explain service design failures and breakdowns. Within the span of a concise article, Ing develops no fewer than eight system theories, each revealing patterns and lessons for service system design: Normann and Ramirez' theory of the offering, Language Action Perspective, Ackoff's target states, Supply side sustainability, Causal texture theory (Emery and Trist), Brand's pacing layers, Holling's Panarchy, and Lewin's action research. Ing's proposal recommends essentially the evolution of "unbounded systems thinking" as an evolution of design thinking. As with many of the works included here, Ing's work initiates a continuing conversation about the relevance of theory to critical design outcomes, and it calls for "building upon."

Andrew McCollough, DeAunne Denmark and Donald Harker propose a view toward design as effective group decision making for complex settings (as their work in healthcare) enabled by the mitigation of individual and group cognitive biases. Their model of interliminal design proposes a collaborative methodology for eliciting and revealing biasing distortions in reasoning through the systemic variety available in facilitated group engagements. They provide a framework (inclusive of Kahneman's cognitive biases and groupthink) and a process or "ritual" for systemic inquiry adapted from their development for education and consultative settings.

Alex Ryan, a co-editor of our Practice special issue, presents a framework for systemic design, a theoretically informed expression of advanced techniques for process, policy and public contexts. He focuses on inherent complexity, situations "characterised by complexity, uniqueness, value conflict, and ambiguity over objectives." Ryan's approach leverages three design targets or levels - the mindset of design teams, the methodology, and the methods selected under methodology. He clearly defines the space for methods shared between design and systemics, and discovers opportunities for the practice to evolve in this space. With a strong foundation in both cybernetic behavioural design and complexity, Ryan's systemic design approach integrates the learning from social and scientific theory applied and tested in the milieu of real-world applications.

John Cassel, extending his research from OCAD University's Strategic Foresight and Innovation graduate program, presents a model of non-parametric design as a methodology for rigorous intervention in wicked problems, especially those involving significant risk and decision trade-offs. As a statistician working with Bayesian reasoning and engineering design for complex structured problems, Cassel's approach is effective for non-parametric, unbounded problems that require discovery practices. He characterizes the design process as an unbounded open system that necessitates discovery of appropriate stakeholders and their concerns and judgments, and the discovery of problematics when parameters cannot be known. He acknowledges the unknown costs of discovery in design problem solving, and enables us to see the trade-off for design quality and risk. He extends the Design Exploration Assessment Methodology (DEAM) methodology as non-parametric method (NDEAM), proposing a method for capturing stakeholder properties and their concerns, requirements, and variables for design decision making.

John Darzentas and Jenny Darzentas develop a case for systemics as the basis for product/service design in self-service systems. Citing the complex social problem of accessibility of services in an e-enabled world, their case study and analysis demonstrates how current models of services design and product innovation fail to account for the largerscale human systems of use. Advancing a democratic design approach (based on Design for All), the Darzentas' paper develops an integrated systems thinking and services approach 
within the case of increasingly necessary self-services for an increasingly vulnerable population of users.

Finally, among the original articles in the Theory special issue we have included a book review by Salvatore Cucchiara of (RSD symposium contributor) Harold Nelson and Erik Stolterman's, The Design Way: Intentional Change in an Unpredictable World. The review credits the book with establishing a foundation for systemic design through a systems view of design thinking. As the reviewer Cucchiara works in public sector innovation, the review presents his view of the value and relationship of rigorous systemics in design applications in the public sphere. The book (and review) can be seen as fruitful bridges between systems theory and design practice.

The convergence of systemic theories with design methodologies may represent a pragmatic turn rather than a theoretical one. In all these papers, a real problematic situation in complex design is resolved or enabled by systems-theoretical approaches. The steps from abstract theory to practical research are not that far, as papers from Cassel and Ryan indicate in particular. After absorbing the best functions of explanatory and descriptive theory into methods for problem resolution, at some point we will recognize it as an evolution of design practice.

Toronto, December 2014

Peter Jones

Special Issue Editor

Peter Jones, Ph.D.

Associate Professor

OCAD University, Toronto, Canada, Faculty of Design

pjones@ocadu.ca

\section{References}

Alexander, C. (2002). The nature of order: An essay on the art of building and the nature of the universe. London: Taylor \& Francis.

Archer, B. (1981). A view of the nature of design research. Design: Science: Method, 30-47.

Buchanan, R. (1992). Wicked problems in design thinking. Design Issues, 5-21.

Cross, N. (1982). Designerly ways of knowing. Design Studies, 3(4), 221-227.

Winograd, T., \& Flores, F. (1986). Understanding computers and cognition: A new foundation for design. Boston: Addison-Wesley.

Krippendorff, K. (2006). The Semantic Turn: A New Foundation for Design. London: Taylor \& Francis.

Nelson, H. \& Stolterman, E. (2012). The design way - intentional change in an unpredictable world. ( $2^{\text {nd }}$ ed.). Cambridge, MA: MIT Press. 